RAL et a $i \quad$ A New Model for Solvent Extraction in Columns $12 / 8 / 89$

\title{
A NEW MODEL FOR SOLVENT EXTRACTION IN COLUMNS
}

\author{
R. A. Leonard, M. C. Regalbuto, D. B. Chamberlain, and G. F. Vandegrift
}

\author{
Argonne National Laboratory \\ Chemical Technology Division \\ 9700 South Cass Avenue \\ Argonne, lilinois 60439
}

December 8, 1989

\section{PAPER PROPOSED FOR PUBLICATION IN SEPARATION SCIENCE AND TECHNOLOGY AS PART OF A SPECIAL ISSUE DEVOTED TO THE SIXTH SYMPOSIUM ON SEPARATION SCIENCE AND TECHNOLOGY FOR ENERGY APPLICATIONS HELD AT KNOXVILLE, TENNESSEE ON OCTOBER} 22-27, 1989

\section{DISCLAIMER}

\begin{abstract}
This report was prepared as an account of work sponsored by an agency of the United States Government. Neitner the United States Government nor any agency thereor, nor any of their employees, makes any warranty, express or implied, or assumes any legal liability or responsibility for the accuracy, completeness, or usefulness of any information, apparatus, product, or process disclosed, or represents that its use would not infringe privately owned rights. Reference herein to any specific commercial product, process, or service by trade name, trademark, manufacturer, or otherwise does not necessarily constitute or imply its endorsement, recommendation, or favoring by the United States Government or any agency thereof. The views and opinions of authors expressed herein do not necessarily state or reflect those of the United States Government or any agency thereof.
\end{abstract}

This work supported by the U.S. Department of Energy, Nuclear Energy Research and Development Program, under Contract W-31-109-Eng-38. 
RAL et al A New Model for Solvent Extraction in Columns 12/8/89

\title{
A NEW MODEL FOR SOLVENT EXTRACTION IN COLUMNS
}

\author{
R. A. Leonard, M. C. Regalbuto, D. B. Chamberlain, and G. F. Vandegrift
}

Argonne National Laboratory

Chemical Technology Division

9700 South Cass Avenue

Argonne, Illinois 60439

\section{ABSTRACT}

A new model was developed for analyzing solvent extraction processes carried out in columns. Each column is treated as a series of well-defined equilibrium stages where the backmixing (other-phase carryover) between stages can be large. By including all mass transfer effects in the backmixing value, the same number of stages can be used for all extracted components no matter what their distribution coefficients. This greatly simplifies the calculations required when modeling multicomponent solvent extraction processes. Initial testing shows the new model to be better than either the Height of an Equivalent Theoretical Plate (HETP) or the Height of a Transfer Unit (HTU) method.

\section{INTRODUCTION}

The TRUEX process is a solvent extraction procedure capab!e of separating, with high efficiency, small quantities of transuranic elements (i.e., $\mathrm{Np}, \mathrm{Am}, \mathrm{Pu}$, and $\mathrm{Cm}$ ) from aqueous nitrate or chloride solutions that are typically generated in nuclear operations, see Horwitz and Schulz (1). The process effluent that contains most of the dissolved solids is sufficiently separated from TRU elements to warrant disposal as a nonTRU waste. 
RAL et al A New Model for Solvent Extraction in Columns $12 / 1 \mathrm{i} / 89$

A computer program called the Generic TRUEX Model (GTM) is being developed so that one can easily evaluate the TRUEX process for removing actinides from nuclear waste streams. The GTM consists of three parts. The first part calculates the distribution coefficients for every component at each stage. The second part uses these $D$ values to calculate the concentration of every component at each stage. The third part estimates the cost of building a plant for the process.

The existing GTM algorithm can handle stagewise solvent extraction done in a centrifugal contactor. To increase the usefulness of the GTM program, a means for handling solvent extraction in columns was needed. If such a column model could be developed, it could take advantage of the distribution coefficients generated by the Generic TRUEX Model. In this paper, we present such a model and use it to analyze pulsed column data for cerium. The results look very encouraging.

Finally, we looked at some additional topics related to modeling columns. These topics include (1) a model for the separating zone of a column, (2) the conversion of the modeling equations from molar to molal units, and (3) key points to watch for when setting up a column model and comparing model calculations with actual data.

\section{PREVIOUS MODELS}

Most previous models for liquid extraction in columns, see Treybal (2), involve use of either the Height Equivalent to a Theoretical Stage (HETS) or the Height of a Transfer Unit (HTU). While the HETS method is simple, breaking the column up into that number of theoretical stages required to obtain the observed separation for a componer:t, it varies widely with changes in such important factors as the flow rate, concentration, or component type. The HTU method, introduced io improve on the HETS method, does not have stages that are appropriate for use in the GTM. Conversion techniques to obtain an appropriate stage height, e. g., the HETS, involve the extraction factor for the component, that is, the organic-to-aqueous flow ratio $(R)$ times 
RAL et al A New Model for Solvent Extraction in Columns $12 / 11 / 89$

the distribution factor (D) for a component. Thus, the number of stages for each component will typically be different because their $D$ values typically are different. The different number of stages for each component would be hard to handle in the GTM since the concentration of each component in a stage is a part of the calculation to determine the distribution coefficient of every component in the stage.

Two other general problems with the HTU method are as follows. First, a number of quantities are hard to determine, specifically, the surface area for the dispersed phase and the overall mass transfer coefficient for each component. Second, the conversion of HTU to HETS has only been worked out for components at dilute concentrations with constant $D$ values.

More recently, new models, which include the effects of backmixing, have been proposed for liquid extraction columns, see Geldard and Beyerlein (3), Nabeshima et al. (4), Misek and Rod (5), King (6), and Sleicher (7). These models reflect a growing recognition that backmixing is important, see Hanson (8). In addition, backmixing of the continuous phase has been observed experimentally, see Godfrey et al. (9), Geier (10), and Ingham (11). However, in these column models that incorporate the effects of backmixing, the area of the dispersed phase and the overall mass transfer coefficient are also included. Thus, the final model is even more complex than the HTU method and still contains the problems that make the HTU method unacceptable for the Generic TRUEX Model.

\section{NEWMODEL}

Because of these problems with the existing models for liquid extraction in columns, especially the problem of a different number of stages for each component, we developed a new model based only on backmixing. The new column model treats extraction in a column as a series of well-defined stages where the backmixing (other-phase carryover) for either phase at each stage can be large. Since this model applies to all components regardless of their $D$ value, the same number of process stages will be appropriate for all components, greatly 
simplifying modeling for the Generic TRUEX Model. The basic assumption of this new column model is that the concentration profiles in a column can be defined in terms of two parameters, ecilitibrium stage height $\left(H_{\mathrm{s}}\right)$ and backmixing. These two parameters are specific for a particular set of column conditions and are interdependent; however, only one condition of $H_{s}$ and backmixing will allow the use of equilibrium distribution ratios for ali components. The value of $H_{s}$ can be attributed to mass transfer due to diffusion and droplet coalescence; any additional effects due to the bulk mass transfer are embodied in the backmixing.

Two sets of backmixing equations are given for the new model. A first approximation allows one to estimate the effect that backmixing will have on components with different $D$ values. This approximation works when the backmixing is low. When backmixing is high, a complete set of flow equations must be used. These equations allow one to calculate the appropriate flow rates for any amount of backmixing. Finally, using either of these two backmixing forms, the equations needed to determine the concentration profile for each component are given.

\section{First Backmixing Approximation}

As a first approximation to the new model, it was assumed that backmixing (other-phase carryover) was small so that the actual flow of the phase being carried back could be ignored. To compensate for the effect of this flow, an effective $D$ value, $D_{\text {eff, }}$ is used in place of the true value. From material balance considerations, it can be shown that this $D_{\text {eff }}$ value is given by

$$
D_{\text {eff }}=\left(D+f_{0, i}\right) /\left(1+f_{a, i} D\right)
$$

where $f_{0, i}$ is the fraction of aqueous phase in the organic phase leaving the stage; and $f_{a, i}$ is the fraction of organic phase in the aqueous phase leaving the stage. While Eq. 1 is not recommended for the model, it does give one a quick way to estimate how backmixing will affect the $D$ value for a component. In particular, one can see that (1) the 
RAL et al A New Model for Solvent Extraction in Columns 12/11/89

backmixing of the organic phase in the aqueous phase becomes important to component separation as the $D$ value for a component becomes much greater than 1.0, and (2) the backmixing of the aqueous phase in the organic phase becomes important to component separation as the $D$ value for a component becomes much less than 1.0 .

Flow Equations for High Backmixing

To solve the flow equations for high amounts backmixing, the input data indicated on the schematic of a column stage for the new model (see Fig. 1) must be specified. Besides the $f_{0, i}$ and $f_{a, i}$ quantities already defined for stage $i$, one needs to specify (1) the volumetric flow rate for the organic and aqueous feeds to stage $i, q_{f, 0, i}$ and $q_{f, a, i}$, respectively, and (2) the fraction of the organic and aqueous streams from stage $i$ that is taken as an effluent, $f_{e, 0, i}$ and $f_{e, a, i}$, respectively, In this model, it is assumed that the $f_{0, i}$ and $f_{a, i}$ apply only to that part of the exiting stage stream which is not taken as an effluent. If the effluent stream does have some of the other phase in it, this can be modeled by specifying that that amount be taken as effluent from the other phase as it exits the stage.

Based on the known (input) data shown in Fig. 1 and the unknown flows, $q_{0}, i$, the organic flow rate out of stage $i$ in the expected direction, and $q_{2, i}$, the aqueous flow rate out of stage $i$ in the expected direction, the various flow rate terms into and out of stage $i$ can be formed as shown in Fig. 2. Writing material balance equations for these flows in the general stage $i$, the organic flow rate is

$$
\begin{array}{rlr}
q_{0, i}= & q_{f, 0, i}+\left(1-f_{e, 0, j-1}\right) q_{o, i-j}+R_{a, i}\left(1-f_{e, a, j+1}\right) q_{a, i+1} \\
& -R_{a, i}\left(1-f_{e, a, i}\right) q_{a, i}, \quad 2 \leq i \leq m-1
\end{array}
$$

where $m$ is the total number of stages in the column. For the corresponding aqueous flow rate

$$
\begin{aligned}
q_{a, i}= & q_{f, a . i}+\left(1-f_{e, a, i+1}\right) q_{a, i+i}+R_{0, i-1}\left(1-f_{e, 0, i-1}\right) q_{o, i-1} \\
& -R_{0, i}\left(1-f_{e, 0, i}\right) q_{0, i}, \quad 2 \leq i \leq m-1
\end{aligned}
$$


RAL et al A New Model for Solvent Extraction in Columns 12/11/89

In these two equations, the quantities $R_{0, i}$ and $R_{a, i}$ are the ratios of the other phase to the main phase. These ratios, which depend on the amount of backmixing, are given by

$$
R_{0, i}=f_{0, i} /\left(1-f_{0, i}\right)
$$

and

$$
R_{a, i}=f_{a, i} /\left(1-f_{a, i}\right)
$$

Note that $R_{0, i}$ and $R_{a, i}$ are equivalent to the fraction of other phase carried along with the main phase, $f_{0, i}$ and $f_{a, i}$, respectively. When $i=1$, Eqns. 2 and 3 become

$$
q_{o, i}=q_{f, o, i}+R_{a, i}\left(1-f_{e, a, i+1}\right) q_{a, i+1}
$$

and

$$
q_{a, i}=q_{f, a, i}+\left(1-f_{e, a, i+1}\right) q_{a, i+i}-R_{0, i}\left(1-f_{e, 0, i}\right) q_{0, i}
$$

respectively, since the $i-1$ terms disappear and $f_{e, a, 1}$ is 1.0. When $i=m$, Eqns. 2 and 3 become

$$
q_{0, i}=q_{f, 0, i}+\left(1-f_{e, 0, i-1}\right) q_{0, i-i}-R_{a, i}\left(1-f_{e, a, i}\right) q_{a, i}
$$

and

$$
q_{a, i}=q_{f, a, i}+R_{0, i-1}\left(1-f_{e, 0, i-1}\right) q_{0, i-1}
$$

respectively, since the $i+1$ terms disappear and $f_{e, 0, m}$ is 1.0 .

Thus, for a column with $m$ stages, there are $2 m$ linear equations with $2 m$ unknowns $\left(q_{0}, i\right.$ and $\left.q_{a, i}, i=1, \ldots, m\right)$. These equations can be solved for $q_{0, i}$ and $q_{a, i}$ by a number of standard techniques. One such technique is the method of determinants commonly called Cramer's rule, see Hohn (12). A second such technique is matrix inversion, see Hohn (12) or Hildebrand (13). Also available is a series of Gauss elimination techniques including the Gauss, Gauss-Jordan, and Crout reductions, see Hildebrand (13). These flow rates are then used to get 
RAL et al A New Model for Solvent Extraction in Columns 12/11/89

the concentration of each component for both phases in every stage.

These concentration calculations are described next.

\section{Component Concentration Equations}

With $q_{0, i}$ and $q_{a, i}$ calculated for all $m$ stages, the unknown concentrations for the aqueous and organic phases in stage $i$ ( $x_{i}$ and $y_{i}$, respectively, $\mathrm{i}=1, \ldots, \mathrm{m})$ can now be determined. Note that this derivation is done for one specific component $j$. The subscript $j$ is not shown here as a matter of convenience.

First it is assumed that one can determine the distribution coefficient $D_{i}$ for each stage $i$. Since these are assumed to be equilibrium stages,

$$
D_{i}=y_{i} / x_{i}
$$

Thus, all $y_{i}$ values for component $j$ can be replaced by $D_{i} x_{i}$ in the material balance equations for component $j$. The final material balance equation for stage $i$ is

$$
a_{i} x_{i-1}+b_{i} x_{i}+c_{i} x_{i+1}=d_{i}
$$

where

$$
\begin{array}{cc}
a_{1}=0 & 2 \leq i \leq m \\
a_{i}=-\left(1-f_{e, 0, i-1}\right)\left(d_{i-1}+R_{0, i-1}\right) q_{0, i-1}, & 1 \leq i \leq m \\
b_{i}=\left[D_{i}+R_{0, i}\left(1-f_{e, 0, i}\right)\right] q_{0, i}+\left[1+R_{a, i}\left(1-f_{e, a, i}\right) D_{i}\right] q_{a, i} & 1 \leq i \leq m-1 \\
c_{i}=-\left(1-f_{e, a, i+1}\right)\left(1+R_{a, i+1} D_{i+1}\right) q_{a, i+1}, & 1 \leq 1 \\
c_{m}=0
\end{array}
$$

and

$$
d_{i}=x_{f, i} q_{f, a, i}+y_{f, i} q_{f, o, i}, \quad 1 \leq i \leq m
$$


RAL et al A New Model for Solvent Extraction in Columns 12/11/89

In addition, since all of the aqueous phase is taken as effluent at stage 1 and all of the organic phase is taken as effluent at stage $m$,

$$
f_{e, a, 1}=1
$$

and

$$
f_{e, 0, m}=1
$$

respectively. This forms the set of $m$ equations for component $j$.

Thus, for a column with $m$ stages, there are $m$ linear equations with $m$ unknowns $\left(x_{i}, i=1, \ldots, m\right)$ for component $j$. To solve this set of linear equations, the techniques cited above for the flow rate equations can be used. However, because the coefficients for this set of equations form a tridiagonal matrix, see Walas (14), the Thomas algorithm can also be used, see King (6) or Carnahan et al. (15). After the $x_{i}$ values for component $j$ are determined at every stage, the $y_{i}$ values can be calculated from Eq. 10. This completes the solution of the component concentration equations.

One further note on the choice of $q_{0}, i$ 's and $q_{a}, i$ 's to be used in the concentration calculations. Normally, one would use the flow equations for high backmixing. However, if one does use $D_{\text {eff }}$ to give an approximation to backmixing, then the $f_{0, i}$ 's and $f_{a, i}$ 's (actually the $R_{0, i}$ 's and $R_{a, i}$ 's) in the $a_{i}{ }^{\prime} s, b_{i}{ }^{\prime} s$, and $c_{j}$ 's become zero while the $D_{i}$ 's are

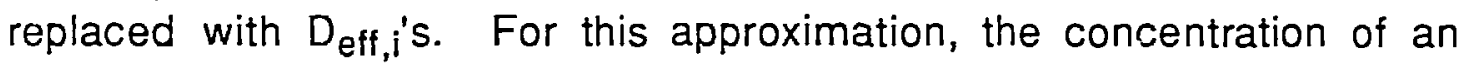
exiting stream reflects the average concentration of both phases in the stream. This can sometimes cause problems when calculated stage concentrations are being compared with actual concentrations. For example, this problem will occur when components have high $D$ values in the extraction section or low $D$ values in the stripping section. Thus, even when the other-phase carryover is low, the use of the flow equations for high backmixing is still recommended. 
RAL et al A New Modei for Solvent Extraction in Columns 12/11/89

\section{Spreadsheet Use}

The above equations can be solved in a number of ways. One way that we have found to be very convenient is the use of spreadsheets (electronic worksheets). A previous article, see Leonard (16), has already discussed the use of electronic worksheets for solvent extraction calculations. Since that article was written, we have rearranged the worksheet, as shown in Fig. 3, and taken advantage of new spreadsheet features such as iterative calculations and matrix inversion. All the information for stage $i$ is in column $i+1$; and column 1 is used to label the values in each row. The aqueous phase concentrations, $x_{i}$ 's, are found in the component concentration section with a certain number of rows set aside for each component. The organic phase concentrations, $y_{i}$ 's, for component $j$ are just below the aqueous phase concentrations for component $j$. Because the distribution coefficient section has a $D$ value for each component at every stage, one is not limited to a constant $D$ value for each component. In fact, one can use equations to calculate $D$ values for one or more components. These equations can be iterative and can depend on the concentration of one or more components in the stage, including the component whose $D$ value is beirig calculated. The arrows between the distribution coefficient section and the component concentration section in Fig. 3 are there to indicate this type of iterative calculation. Thus, this spreadsheet algorithm for stagewise solvent extraction, which we call SASSE, is very powerful and yet very easy to set up and use.

In the modeling of test results reported below, the matrix inversion technique was used on the $2 \mathrm{~m}$ linear equations for high backmixing (Eqns. 2 through 9 ) to obtain the $q_{0, i}$ 's and $q_{a, i}$ 's. On the spreadsheet layout shown in Fig. 3 , the matrix inversion was done below the layout so that it was out of the way. The time to run this SASSE worksheet using Microsoft Excel 2.2 on a Macintcsh II personal computer with 14 process (column) stages, 5 components, and the $D$ values given rather than calculated is 20 seconds. When $D$ values must be calculated through an iterative process, the calculational time is 
RAL et al A New Model for Solvent Extraction in Columns 12/11/89

around 60 seconds. Because Excel has excellent charting capabilities, one can set up a chart to see immediately the change in concentration profile for one or more of the components.

\section{DATA ANALYSIS}

Extraction column data must be evaluated in the following way to obtain good model values for the stage height, $H_{S}$, and the fraction of dispersed phase flow that is actually continuous phase, $f_{d, j}$, in stage $i$. Note that, if the aqueous phase is the continuous phase, then $f_{d, i}$ is $f_{0, i}$. Conversely, if the organic phase is the continuous phase, then $f_{d, i}$ is $f_{a, i}$. For each component to be analyzed, one must have its $D$ value throughout the column, its feed concentration, and its effluent concentration in hoth phases, especially the same chase after the component has been extracted or stripped. In addition, one needs to know the O/A flow ratio in the column, the continuous phase in the column, and the height of the section in which the extraction or stripping occurred.

Given this information, one sets up a SASSE worksheet with a small number of stages and a small amount of backmixing for each phase, typically, $0.5 \%$. If one can not achieve the observed separation, the number of stages is increased until the calculated separation is greater than the observed separation. Then the amount of backmixing of continuous phase with the dispersed phase is increased until the calculated and observed separations match. Because the section height is known, the stage height can be calculated for the calculated $f_{d, i}$ value. The number of stages is increased again and new values for $H_{s}$ and $f_{d, i}$ are calculated. This process is repeated several times so that one obtains a locus of points, all of which could characterize the model for this component. To determine which point of all these points is the appropriate one to use in the model, curves showing the locus of possible operating points are generated for several components that span the range of $D$ values in the column. The common intersection point of all these curves gives the appropriate $H_{s}$ and $f_{d, i}$ values to be used in the model. 
RAL et al A New Model for Solvent Extraction in Columns 12/11/89

When, as is the case for the test of the new model discussed next, the data are from t'vo different columns, the operating conditions with respect to plate geometry, plate spacing, pulse amplitude, and pulse frequency should be the same. In addition, the extraction factor (RD) should be sufficiently different so that the locus of possible operating points for the various cases will intersect rather than form a series of overlapping or parallel curves.

In analyzing column data as well as modeling columns, one should note carefully where the individual columns are. While backmixing can be quite high within a column, the separating zone at each end of a column limits the amount of other-phase carryover between columns. If the amount of other-phase carryover between columns is not known, a sriall value, e. g., $0.5 \%$ or $0.1 \%$, should be used. Because of the way that the flow equations are set up with the backmixing (other-phase carryover) specified at each stage for both phases, this modeling of distinct columns within an overall system is easy to implement.

\section{IEST OF THE NEW MODEL}

To test the new model, data from pulsed column tests at the Idaho Chemical Processing Plant (ICPP), see Maxey et al. (17), were used. The pulsed columns had sieve plates $(3.2 \mathrm{~mm}$ dia holes with $25 \%$ free area) with a spacing of $50.8 \mathrm{~mm}$ in a column. Each column had a diameter of $50.8 \mathrm{~mm}$. The heights of the extraction and scrub sections in the extraction/scrub column were 5.06 and $1.56 \mathrm{~m}$, respectively. The height of the stripping section in the stripping column was $2.86 \mathrm{~m}$. Both columns were operated in the aqueous-continuous mode. Except as noted, the pulse frequency was 40 cycles per minute. In all cases, the pulse amplitude was $25.4 \mathrm{~mm}$. The organic solvent consisted of $20 \%$ dihexyl-N,N-diethylcarbamyimethylenephosphonate (DHDECMP) in a diluent that is a 2:1 mixture of decalin and diisopropylbenzene. The aqueous phase consisted of $\mathrm{HNO}_{3}, \mathrm{Ce}\left(\mathrm{NO}_{3}\right)_{3}$, and other nitrate salts. 
RAL et al A New Model for Solvent Extraction in Columns 12/11/89

\section{Ce Extraction/Scrub Runs}

Analysis of two extraction/scrub runs was done using the above technique. Since the extraction factors for both runs were close (D values are $4.5 \pm 0.5$ and $\mathrm{O} / \mathrm{A}$ flow ratios are $0.41 \pm 0.05$ in the extraction section of the column), the locus of operating points forms parallel curves. This is seen for Runs 11 and 20 in Fig. 4. A third run, Run 7, made at the same conditions, but with a pulse frequency of $3 \mathrm{~J}$ cycles per minute, also lies within this family of curves. Alsc shown in Fig. $4^{-}$is the curve obtained if the organic phase is wrongly assumed to be the continuous phase for Run 7. As can be seen; this curve is very different from the aqueous-continuous curve for Run 7. This comparison shows how important it is to know which phase is the continuous phase when using the new model.

For Run 20, the concentration of $\mathrm{Ce}$ in the aqueous feed is 10 times that for Runs 7 and 11 , that is, $2.2 \mathrm{~g} / \mathrm{L}$ rather than $0.22 \mathrm{~g} / \mathrm{L}$. Because of this, the $D$ value in the extraction section is 4 rather than the 5 used for Runs 7 and 11 . In all three runs, the $D$ value in the scrub section is 4 . Figure 4 shows the curve obtained when a $D$ value of 5 is wrongly used for the extraction section of Run 20. As can be seen, this curve, which is displaced far to the right, is very different from the proper curve for Run 20 and the appropriate curves for the other two runs. This comparison shows how important it is to have accurate $D$ values when a component is being analyzed.

\section{Ce Stripping Runs}

Analysis of two stripping runs was also done with the above technique. Since the extraction (stripping) factors for both runs were close ( $D$ values are about 0.1 and O/A flow ratio is 1.0), the locus of operating points forms parallel curves. This is seen for Runs 3 and 5 in Fig. 5. Since the concentration of $\mathrm{Ce}$ in the organic feed was essentially identical, $0.45 \mathrm{~g} / \mathrm{L}$ and $0.46 \mathrm{~g} / \mathrm{L}$, for Runs 3 arid 5 , the only variation in modeling these two runs is the Ce concentration in the organic product effluent, which was $0.020 \mathrm{~g} / \mathrm{L}$ for Run 3 and $0.015 \mathrm{~g} / \mathrm{L}$ for Run 5. As can be seen in Fig. 5, there is a considerable distance 
RAL et al A New Model for Solvent Extraction in Columns 12/11/89

between these two curves because of this difference in the effluent concentrations. This comparison shows how important it can be to have accurate effluent concentrations when a component is being analyzed.

\section{Column-Specific Model}

Once these two sets of runs are analyzed, their average values are plotied on a sirigle chart, as shown in Fig. 6 . Since each curve represents the locus of points that would be satisfactory for modeling each section, the intersection of these two curves gives a single stage height, $H_{S}$, and a single backmixing (other-phase carryover) fraction of the dispersed phase, $f_{d, i}$, which should now correlate all components in these and other sieve plate columns with the same plate geometry, plate spacing, pulse frequency, and pulse amplitude. In this case, the results show that a stage height of $0.65 \mathrm{~m}$ and a fraction (backmix ratio) of $0.35(35 \%)$ for the continuous aqueous phase being carried up the dispersed organic phase will correlate all the data. As noted above, a small fraction of $0.005(0.5 \%)$ for the dispersed organic phase beirig carried down with the continuous aqueous phase as it leaves the column stage is also included in the model.

A comparison of calculated results from this new backmix model for pulsed columns with two prior methods is given in Table 1. The range for the new backmix model is obtained by holding the backmix ratio at $0.35(35 \%)$ and observing the range of stage heights, $H_{s}$, for this ratio. The ranges for HETS and HTU were obtained from Maxey et al. (17) for the same four runs. As can be seen from the table, the range of heights is smallest for the new backmix model. Thus, the use of $H_{s}$ rather than HETS or HTU seems to give a better fit of the data. In addition, and most important, the same stage heighi (and so, the same number of stages in a column) can be used for all components regardless of their $D$ value and $O / A$ flow ratio.

\section{SEPAPATING ZONE MODEL}

Another model for solvent extraction in columns is proposed for the separating zone which occurs at either the top or the bottom of the 
RAL et al A New Model for Solvent Extraction in Columns 12/11/89

column. This separating zone is the space where the dispersed phase droplets coalesce to form a continuous phase that becomes the dispersed-phase effluent. Based on the work of Leonard et al. (18), the dispersion number, $N_{D i}$, is fairly constant for a given solvent pair ir the continuous phase is known. For solvents which use normal dodecane or similar normal paraffin hydrocarbons as the diluent, $\mathrm{N}_{\mathrm{Di}}$ is about $8 \times 10^{-4}$ if the organic phase is the continuous phase and about twice that if the aqueous phase is the continuous phase. For batch tests, $N_{D i}$ is given by

$$
N_{D i}=(\Delta z)^{0.5} /\left(g^{0.5} t_{B}\right)
$$

where $g$ is gravitational acceleration, $t_{B}$ is the time for the dispersion to break, and $\Delta z$ is the initial thickness of the dispersion. For continuous flow tests in gravity systems, $N_{D i}$ is given by

$$
N_{D i}=(\Delta z)^{0.5} /\left(g^{0.5} t_{R}\right)
$$

where $g$ is gravitational acceleration, $t_{R}$ is the residence time in the dispersion band, and $\Delta z$ is the thickness of the dispersion during steady-state operations.

Application of the $\mathrm{N}_{\mathrm{Di}}$ to the design of the separating zone in a solvent extraction column would go as follows. The $N_{D i}$ for the solvent pair would be measured on the benchtop using Eq. 20. The residence time would be calculated using

$$
t_{R}=A_{s z} \Delta z / q_{T}
$$

where $A_{s z}$ is the cross-sectional area of the separating zone, $q_{T}$ is the total flow rate of the two phases, and $\Delta z$ is the thickness of the dispersion in the separating zone. Combining Eqns. 21 and 22 and solving for $\Delta z$ give

$$
\Delta z=\left[q_{T} /\left(A_{s z} N_{D i}\right)\right]^{2 / g}
$$

Equation 23 allows one to balance the values for $A_{S z}$ and $\Delta z$ to obtain an appropriate size for the separating zone. In applying this equation, use a conservative value for $N_{D i}$, i.e., about $50 \%$ of the normal $N_{D i}$ value, 
RAL et al A New Model for Solvent Extraction in Columns $12 / 11 / 89$

because $N_{D i}$ is based on less than $1 \%$ other-phase carryover. With this lower $\mathrm{N}_{\mathrm{Di}}$ value, other-phase carryover would typically be closer to $0.1 \%$. In addition, the appropriate flow rate to use would be a value that is between that for the dispersed phase and $q_{T}$. The use of $q_{T}$ is a conservative choice which is appropriate when experimental data are not available.

\section{OTHER MODEL TOPICS}

For the above calculations, concentrations are in molar (쓰) units with volumetric flow rates in L/min. If it is desired to work in molal (m) units instead, the same equations apply: hwever, orie must give the flow rates in $\mathrm{kg}$ of solverit/minute and the values in molal units. Also, the O/A flo's rates will have units of $\mathrm{kg}$ of solvent/min for each phase. In the aqueous phase, the solvent is water. In the organic phase, the solvent is the extractarit dissolved in the diluent or diluents.

In the above discussion, the backmixing term, $f_{d, i}$, is taken to be a single variable associated with the flow of the dispersed phase, but it is expected that, in general, $f_{d, i}$ will be more complicated. In particular, it is expected that $f_{d, i}$ will have two parts. The one part will be continuous-phase liquid carried along by the dispersed-phase droplets as they move through the continuous phase. The other part will be continuous-phase liquid which is carried in the direction of dispersed-phase flow by its own turbulence. This second part of $f_{d, i}$ will come to the fore when the flow of the dispersed phase is much less than that for the continuous phase. It would be important at very high or very low O/A flow ratios.

Finally, more work needs to be done in this area. This paper only lays out the model and shows how it was successfully applied to the data from one type of solvent extraction column. More testing of the model is necessary to validate it, especially under conditions where several components are followed for a particular set of column operating conditions. A.lso, it would be helpful to know how $f_{d, i}$ and $H_{s}$ vary as plate geometry, plate spacing, pulse amplitude, and pulse frequency change. Along these lines, the intensity of the turbulence in 
RAL et al A New Model for Solvent Extraction in Columns 12/11/89

the column should be useful in developing a more general correlation for this data.

\section{CONCLUSIONS}

A new backmix model for pulsed columns was tested and found to work well. This model is a key step for including pulsed columns in the Generic TRUEX Model. It is important to the GTM because a single stage height, and hence a fixed number of stages, can be used for all components in the pulsed column. This characteristic, a fixed number of stages for all components, should prove useful for modeling many solvent extraction systems. In addition, the new model is implemented in such a way that (1) there can be a different $D$ value at each stage for every component, (2) an aqueous feed or an organic feed or both can be introduced at any stage, (3) an aqueous effluent or an organic effluent or both can be taken from any stage, and (4) it can be set up on a computer spreadsheet that is fast and easy to use.

\section{ACKNOWLEDGMENTS}

This work was supported by the U.S. Department of Energy under Contract W-31-109-Eng-38.

\section{REFERENCES}

1. E. P. Horwitz and W. W. Schulz, "Application of the TRUEX Process to the Decontamination of Nuclear Waste Streams," International Solvent Extraction Conference, Munich, Federal Republic of Germany, September 11-16, 1986, Vol. I, $81-89$ (1986).

2. R. E. Treybal, Liquid Extraction, 2nd ed, McGraw-Hill, New York (1963).

3. J. F. Geldard and A. L. Beyerlein, "CUSEP--A New Mathematical Model of Fulsed Column Contactors Using the PUREX Process," Nucl. Tech. 85,172-186 (1989).

4. M. Nabeshima, M. Kitahara, C. Tanaka, and M. Shuto, "Dynamic Simulation Code 'DYNAC' for the PUREX Cycle Composed of Pulsed 
RAL et al A New Model for Solvent Extraction in Columns 12/11/89

Columns," in Extraction '87: The Recovery of High Value Materials, Institution of Chemical Engineers Symposium Series No. 103, Pergamon Press, Oxford, UK, 307-321 (1987).

5. T. Misek and V. Rod, "Calculation of Contactors with Longitudinal Mixing," in C. Hanson, editor, Recent Advances in Liquid-Liquid Extraction, Pergamon Press, Oxford, UK, 197-236 (1971)

S. C. J. King, Separation Processes, McGraw-Hill, New York (1971).

7. C. A. Sleicher, "Entrainment and Extraction Efficiency of MixerSettlers," AIChE Journal 6, 529-531 (1960).

8. C. Hanson, "Recent Research in Solvent Extraction," Chemical Engineering $75(19), 135-142$ (9-9-68).

9. J. C. Godirey, D. A. Houlton, S. T. Marley, A. Marrocchelli, and M. J. Slater, "Continuous Phase Axial Mixing in Pulsed Sieve Plate Liquid-Liquid Extraction Columns," Chem. Eng. Res. Design 66, 445-457 (1988).

10. R. G. Geier, compiler, Solvent Extraction Equipment Evaluation Studv-- Part 1. Review of the Literature, Battelle Pacific Northwest Laboratories, Richland, WA, BNWL-2186 Pt 1 (1977).

11. J. Ingham, "The Study of Longitudinal Mixing in Liquid-Liquid Contactors," in C. Hanson, editor, Recent Advances in LiquidLiquid Extraction, Pergamon Press, Oxford, UK, 237-291 (1971).

12. F. E. Hohn, Elementary Matrix Algebra, Macmillan, New York (1958).

13. F. B. Hildebrand, Introduction to Numerical Analysis, McGraw-Hill, New York (1956).

14. S. M. Walas, Chemical Process Equipment, Butterworths, Boston (1988). 
RAL et al A New Model for Solvent Extraction in Columns 12/8/89

16. R. A. Leonard, "Use of Electronic Worksheets for Calculation of Stagewise Solvent Extraction Processes," Separation Science and Technology 22(2\&3), 535-550 (1987).

17. H. R. Maxey, D. B. Chamberlain, G. J. McManus, E. L. Colton, and R. L. Nebeker, Removal of Actinides from ICPP Fuel Reprocessing Wastes: Engineering Studies Terminal Report, Exxon Nuclear Idaho Company, Idaho Falls, ID, ENICO-1057 (1980).

18. R. A. Leonard, G. J. Bernstein, R. H. Pelto, and A. A. Ziegler, "LiquidLiquid Dispersion in Turbulent Couette Flow," AIChE Journal 27. 495-503 (1981). 
RAL et al A New Model for Solvent Extraction in Columns 12/11/89

Table 1. Comparison of Stage Height by Three Different

Pulsed Column Models for the Same Four Runs.

Model

Height Equivalent Theoretical

Stage (HETS)

Height Transfer Unit (HTU)

Stage Height $\left(H_{s}\right)$ with $35 \%$ backmixing of the continuous phase
Stage Height for Extraction and Stripping, $m$

$$
0.73-1.50
$$

$$
\begin{gathered}
0.50-0.79 \\
(0.50-4.9 \text { with scrub included })
\end{gathered}
$$




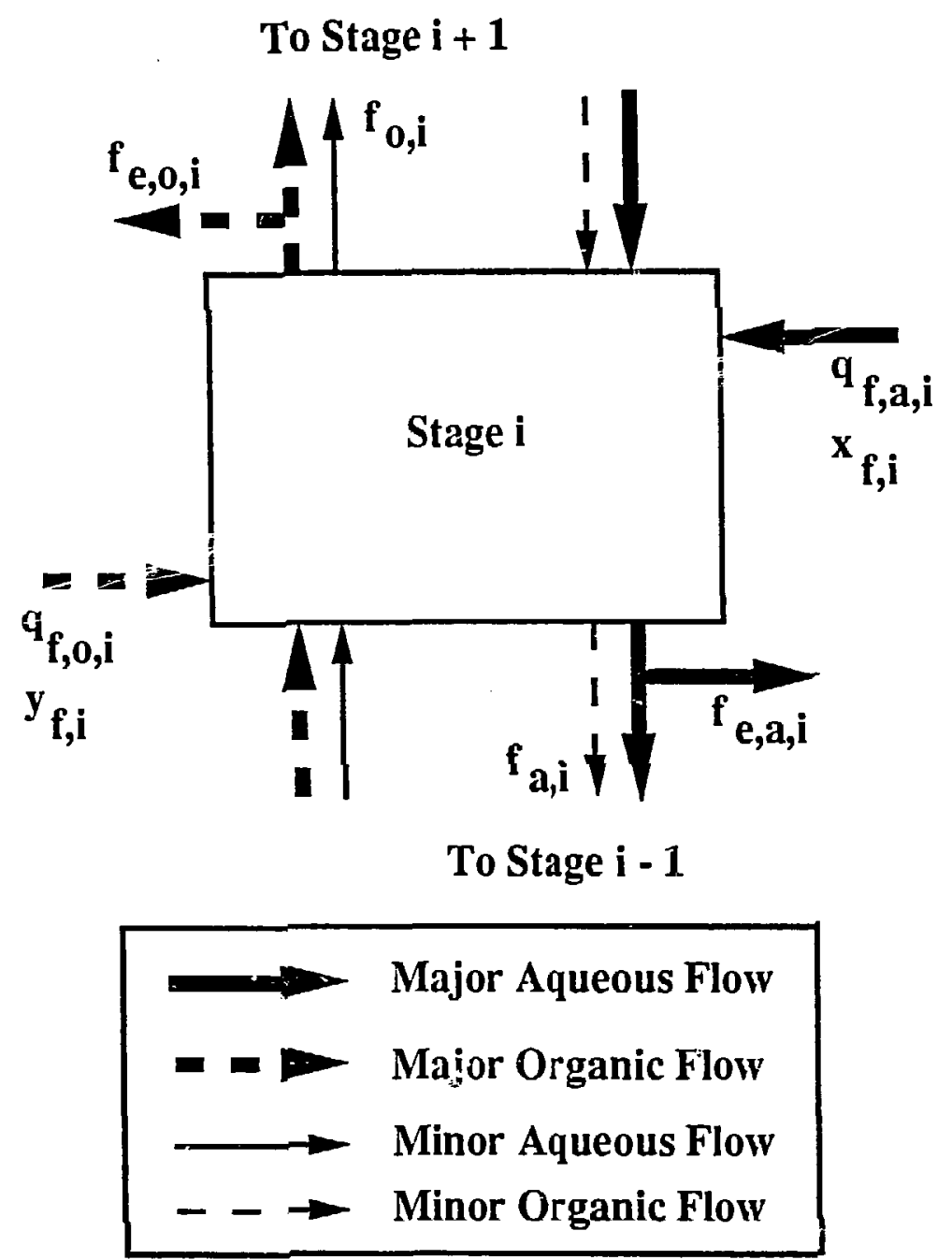

Fig. 1. Schematic for Stage i with User-Specified Quantities Shown. 


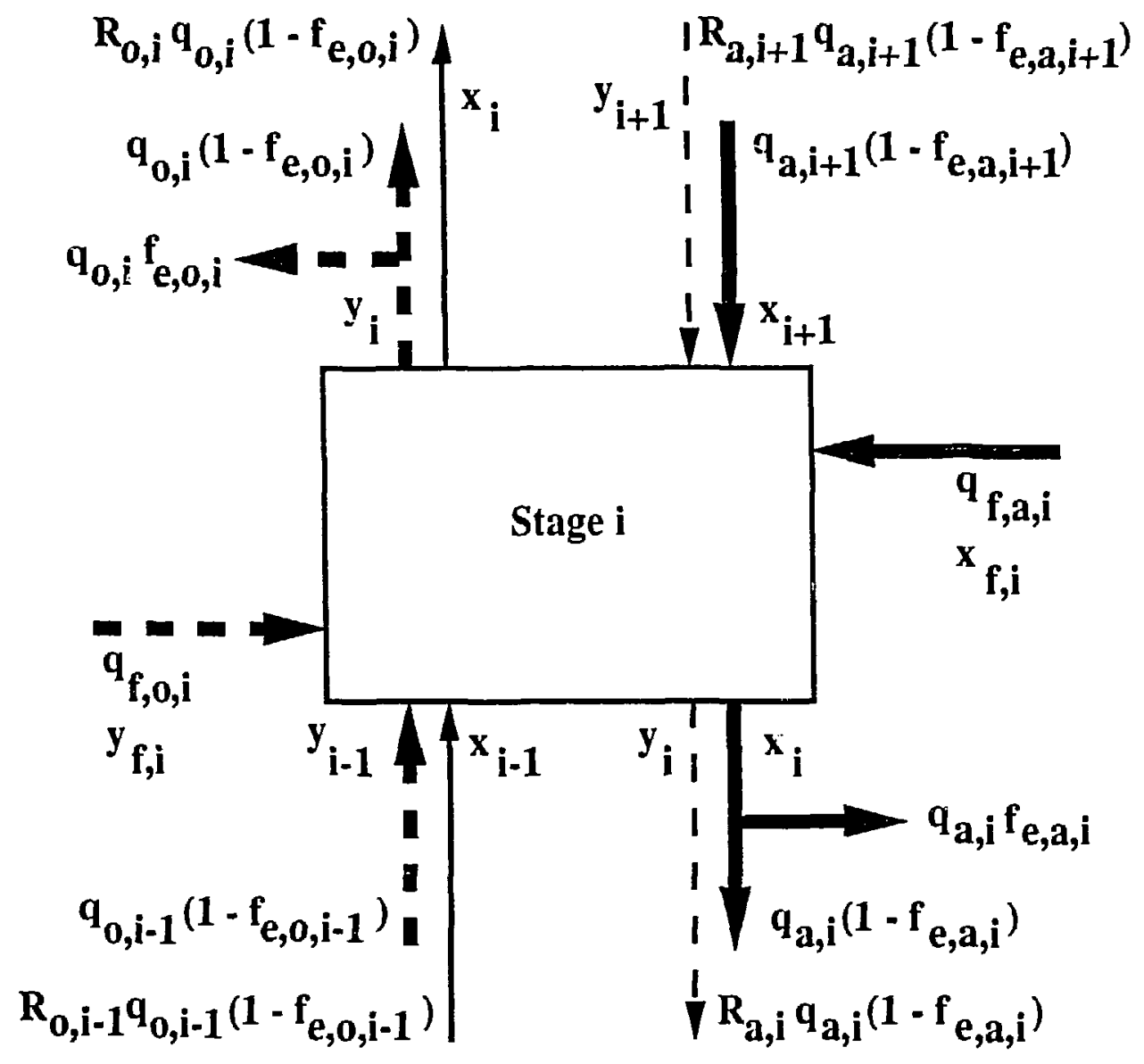

Fig. 2. Schematic for Stage i with Flow Rates and Concentrations Shown. 


\section{General}

Section names

Component names

General notes

Worksheet parameters

\section{Input}

Feed flow rates

Flow fraction out of the process

Other-phase carryover (backmixing)

Feed stream concentrations

Volume of both phases in each stage

\section{Distribution Coefficients}

Value for every component in each stage

Equations to calculate the distribution coefficient

Can be iterative

Can depend on several component concentrations

\section{Results}

Effluent flow rates

Effluent and stage concentrations for every component

Residence time of both phases in each stage

\section{Flow Rates}

Both phases in each stage

\section{Component Concentrations}

Error trap for distribution coefficients

Value for every' component in hoth phases at each stage

Fig. 3. Schematic Showing Snreadsheet Layout for Stagewise Process càculations. 


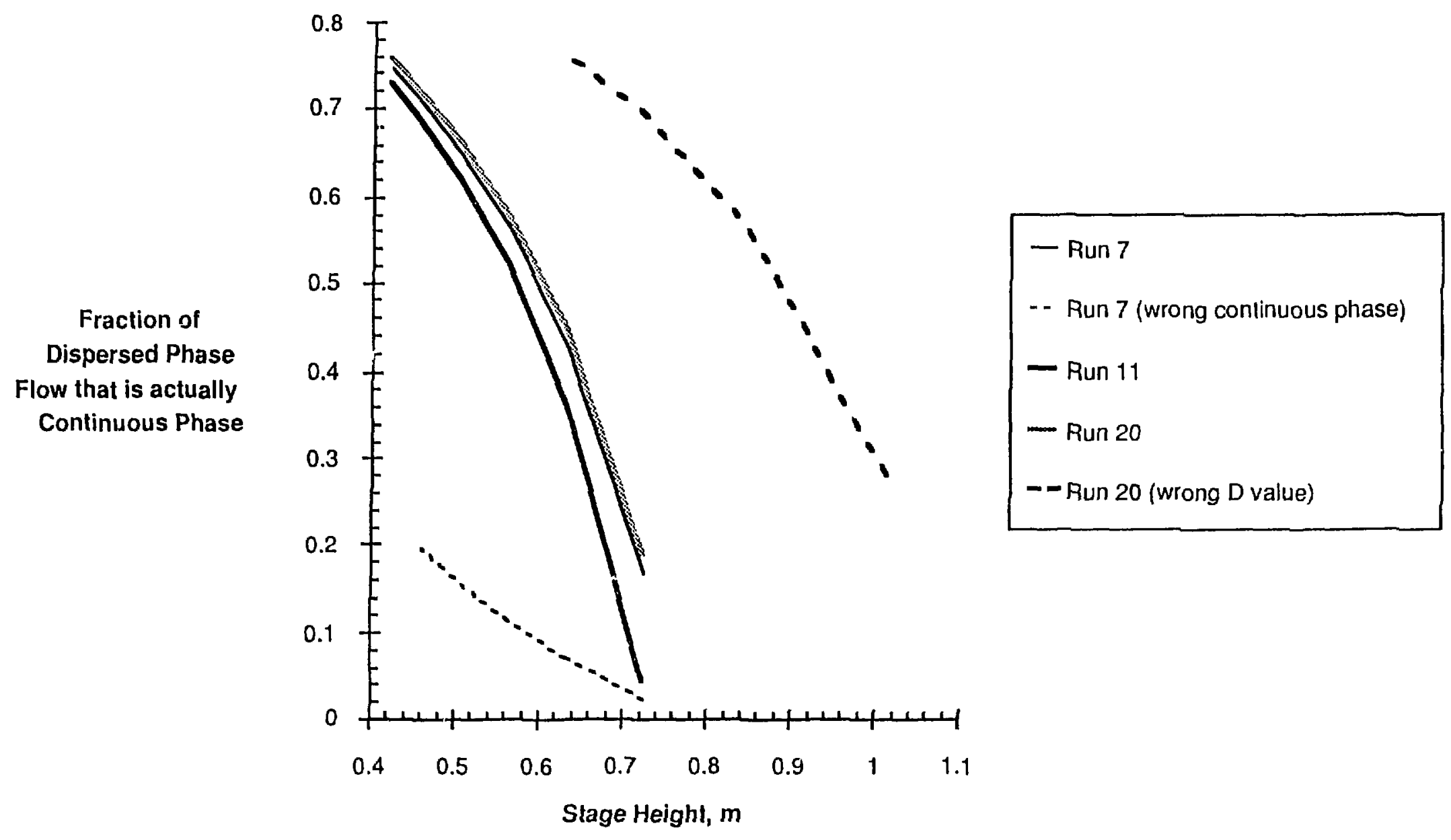

Fig. 4. Locus of Operational Points for Three Extraction/Scrub Runs. 


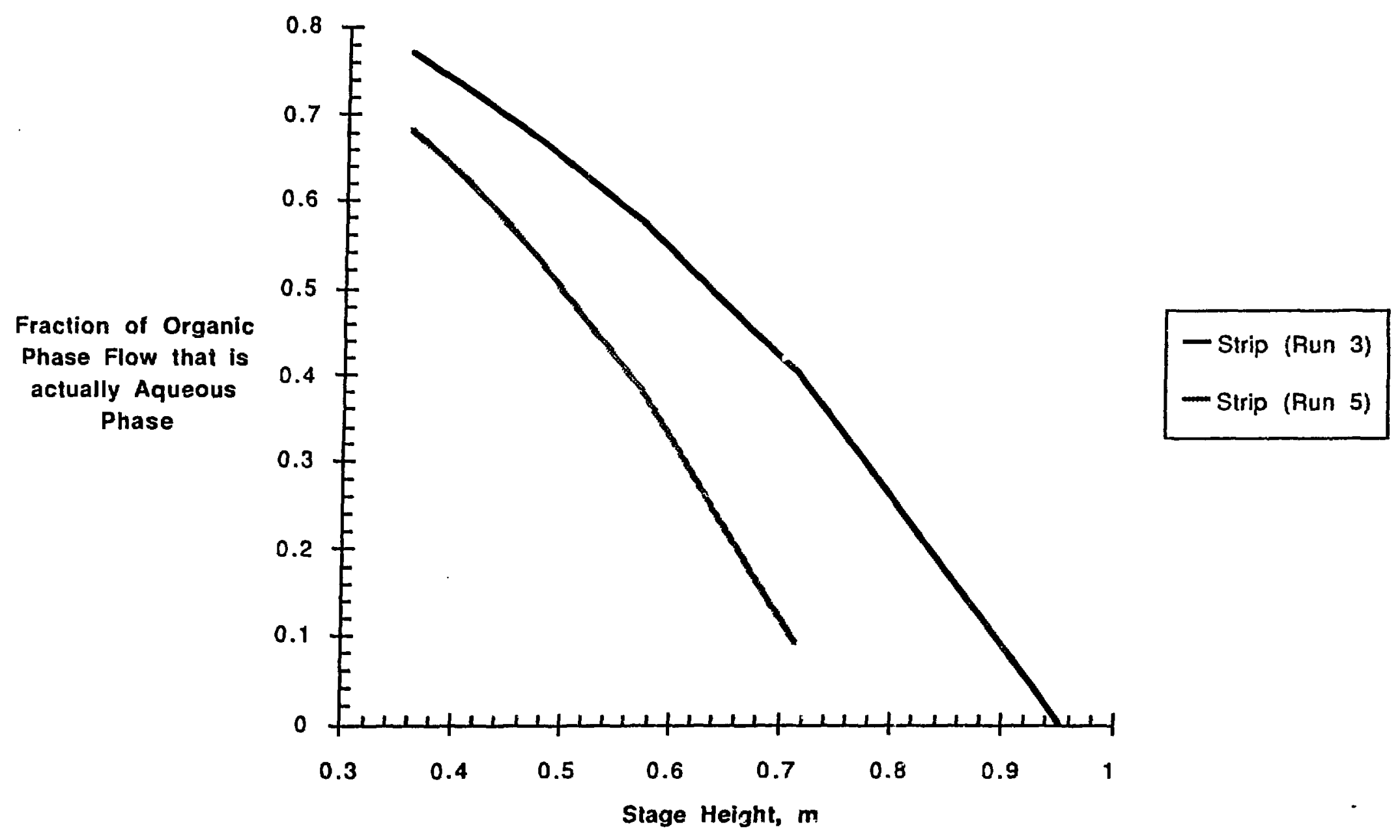

Fig. 5. Locus of Operational Points for Two Stripping Runs. 


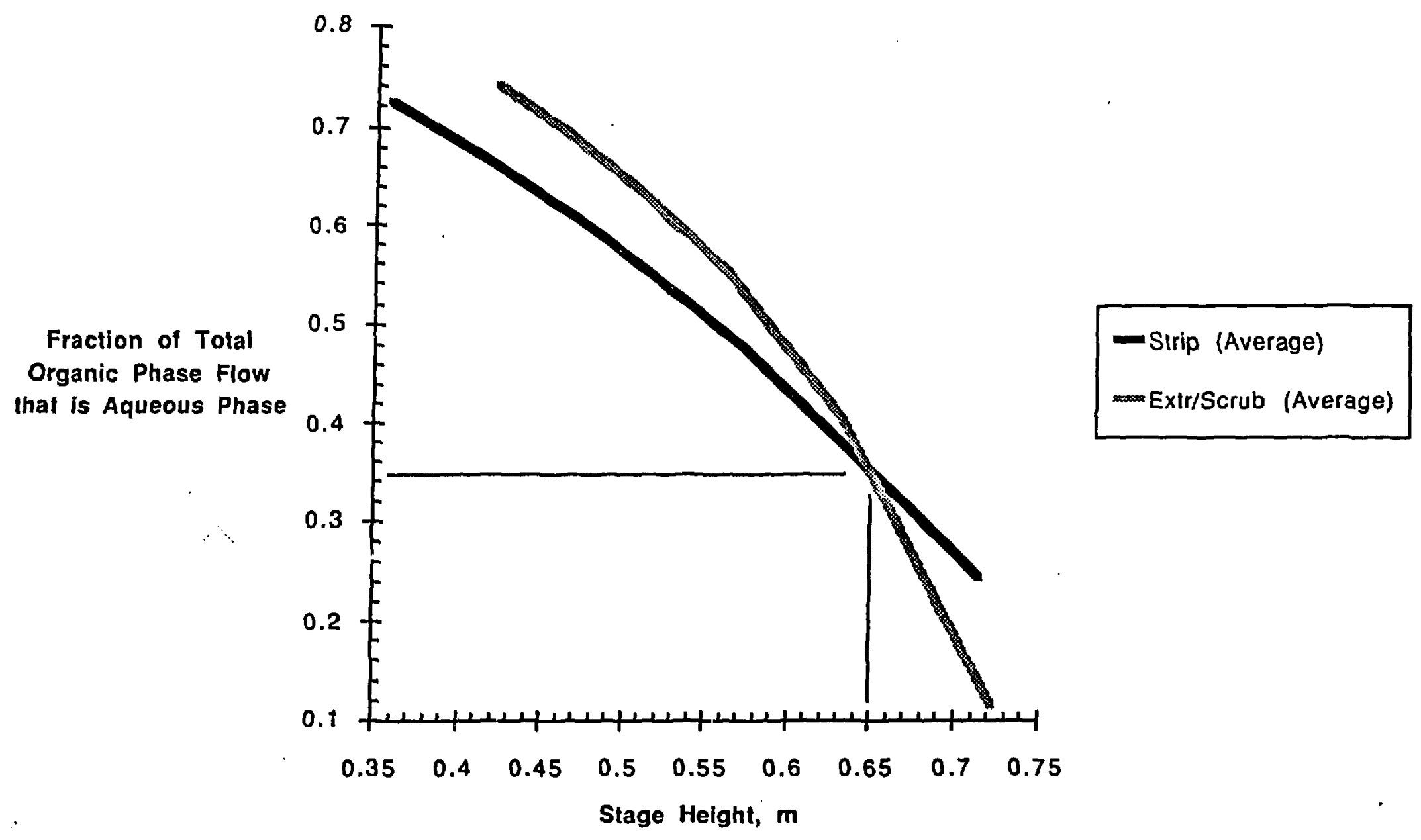

Fig. 6. Intersection of Operational Points for Extraction and Stripping Runs. 